\title{
EFEITO DE DIFERENTES NÍVEIS DE ÁGUA NO SOLO NA PRODUÇÃO DO RABANETE CULTIVADO EM DOIS TIPOS DE AMBIENTES PROTEGIDOS
}

\author{
Elvis Márcio de Casto Lima ${ }^{1}$, André Maller², Anderson Takashi Hara ${ }^{3}$, Fátima Conceição Rezende ${ }^{4}$, Jacinto \\ Assunção Carvalho ${ }^{5}$
}

\begin{abstract}
RESUMO
A cultura do rabanete é sensível às flutuações de umidade no solo, no entanto, são raros os trabalho sobre o manejo da irrigação e o efeito do déficit hídrico. Assim, este trabalho foi conduzido com o objetivo de avaliar o efeito da irrigação na cultura do rabanete cultivado em ambiente protegido. O estudo foi realizado na área experimental do Departamento de Engenharia da UFLA em duas estufas sendo uma coberta com polietileno transparente (convencional) e a outra, também coberta com polietileno foi colocado nas laterais e ao nível do pé direito uma malha vermelha (modificado). A cultura foi irrigada por gotejamento. Utilizou-se um delineamento experimental inteiramente casualizado (DIC), com quatro níveis de tensão de água no solo $(15,30,45$ e $60 \mathrm{kPa})$ e quatro repetições, em um total de 16 parcelas experimentais. As variáveis analisadas foram: diâmetro, comprimento e massa fresca do bulbo com raiz e sem a raiz, área foliar, comprimento da raiz, massa seca da planta, massa seca do bulbo. Os resultados indicam que nos dois ambientes os tratamentos de irrigação não influenciaram nas variáveis analisadas. No ambiente com malha vermelha os valores tendem a serem menores, exceto a área foliar.
\end{abstract}

Palavras-chave: matéria fresca, área foliar, Raphanus sativus

\section{ABSTRACT \\ EFFECTS OF DIFFERENT SOIL WATER LEVELS ON RADISH PRODUCTION CULTIVATED IN TWO TYPES OF PROTECTED ENVIRONMENT}

The radish culture is sensitive to fluctuations in soil water content, however there are few studies on irrigation management and the effect of water deficit. This study was therefore conducted to evaluate the effects of irrigation on radish plants in a greenhouse. The study was conducted in the experimental area of the Department of Engineering, UFLA, in two greenhouses where one was covered with transparent polyethylene (conventional), and the other was also covered with polyethylene but along the lateral base a red mesh was installed (modified). The cultivation was drip-irrigated. A completely randomized design (CRD) was used with four levels of soil water tension (15, 30, 45 and $60 \mathrm{kPa}$ ) and four repetitions, for a total of 16 plots. The variables analyzed were: diameter, length and fresh matter of the bulb with root and without root, leaf area, root length, dry matter of the plant and dry matter of the bulb. The results indicated that in the two environments irrigation treatments did not influence the analyzed variables. In the environment with red mesh the values tended to be lower, except for leaf area.

Keywords: fresh matter, leaf area, Raphanus sativus

Recebido para publicação em 10/12/2014. Aprovado em 29/06/2015.

1 - Eng. Agrícola, Doutorando, Departamento de Engenharia, UFLA, CP 3037, Lavras-MG, e-mail:elviscastrolima@yahoo.com.br

2 - Eng. Agrônomo, Doutorando, Departamento de Engenharia/UEM, Maringá-PR, e-mail:anmaller@hotmail.com

3 - Eng. Agrônomo, Doutorando, Departamento de Engenharia/UEM, Maringá-PR, e-mail:haratakashi@hotmail.com

4 - Eng. Agrícola, Departamento de Engenharia, UFLA, CP 3037, Lavras-MG, e-mail:frezende@deg.ufla.br.

5 - Eng. Agrícola, Professor, Departamento de Engenharia, UFLA, CP 3037, Lavras-MG, e-mail:jacintoc@deg.ufla.br

\footnotetext{
346 REVENG

346-354p.

ENGENHARIA NA AGRICULTURA, VIÇOSA - MG, V.23 N.4, JULHO / AGOSTO 2015
} 


\section{INTRODUÇÃO}

O rabanete (Raphanus sativus L.) pertence à família das Brassicáceas e caracteriza-se por ser uma planta de porte reduzido, que produz raízes globulares, de cor escarlate brilhante e polpa branca comestível. De acordo com Carmichael et al. (2012), o rabanete é um legume rico em vitaminas e minerais e tem valores medicinais sendo usado principalmente para salada e fins decorativos e está em alta demanda na indústria hoteleira. A colheita é realizada entre 20-30 dias após a semeadura, dependendo da estação do ano. A pesar de ser uma cultura de pequena importância, em termos de área plantada, possui boa viabilidade financeira, e, de acordo com Aguila et al. (2007), o retorno econômico é rápido. Conforme os mesmos autores, é uma planta relativamente rústica podendo ser usada como cultura intercalar entre outras de ciclo mais longo.

O teor de água no solo, durante o ciclo da cultura, deve ser mantido próximo da capacidade de campo, evitando flutuações para que não ocorram rachaduras nas raízes (AZEVEDO; SAAD, 2012). $\mathrm{O}$ estresse hídrico ao longo do ciclo da cultura pode alterar seu desenvolvimento, modificando a fisiologia, morfologia e, principalmente, afetando as relações bioquímicas da planta (PEREIRA et al.,1999). Tanto a produtividade quanto a qualidade do rabanete são altamente influenciadas por períodos de seca ou por irrigações mal manejadas (KANG; WAN, 2005).

De acordo com Costa et al. (2006), variações de umidade e temperatura no solo durante o desenvolvimento das plantas podem prejudicar a produtividade e a qualidade das raízes. Em trabalho realizado por Kano e Fukuoka (1995) com rabanete japonês, foi observado que durante o período de crescimento a temperatura do solo em torno de 32 ${ }^{\circ} \mathrm{C}$ induz a rachaduras no bulbo devido a formação de lignina em torno das células. A ocorrência de rachaduras e isoporização (esponjosos e insípidos) são fatores que prejudicam a qualidade do produto.

$\mathrm{O}$ efeito da densidade de plantio sobre a massa e o diâmetro do bulbo de rabanete foram avaliados por Torres et al. (2003) e não foi observado diferença significativa entre os tratamentos, sendo que a massa média da matéria fresca variou de
$22,04 \mathrm{~g}$ a $28,63 \mathrm{~g}$ e o diâmetro médio do bulbo variou de $31,49 \mathrm{~mm}$ a $33,57 \mathrm{~mm}$.

Pereira (2002), trabalhando com rabanete cultivado em túneis com diferentes níveis de perfuração e irrigado por gotejamento, em duas épocas do ano (primavera e inverno), verificou que as características do rabanete (altura, diâmetro e peso do tubérculo) foram mais desenvolvidas no cultivo de primavera, comprovando que a época do ano influencia no desenvolvimento da cultura.

O conhecimento das características de transmissividade da radiação solar pelos materiais utilizados na cobertura das estufas é importante, pois influencia na produtividade e qualidade dos produtos. De um modo geral, os cultivos protegido têm apresentado êxito para algumas espécies comerciais e, portanto, no mercado há várias opções de materiais para proteção das plantas. Holcman e Sentelhas (2013) verificaram que o ambiente com malhas de sombreamento vermelha promoveu as melhores condições para a produção da bromélia. Nomura et al. (2009), trabalhando com quatro malhas de sombreamento (azul, vermelha, preta e termo-refletora) sobre canteiros cultivados com antúrio, verificaram que a malha preta proporcionou melhores condições para o crescimento e produção. Estes resultados indicam que pesquisas utilizando esses materiais devem ser desenvolvidas, pois a resposta das plantas ás alterações microclimáticas são diferenciadas.

Souza et al. (1999), trabalhando com rabanete submetidos a três intensidades de radiação solar, definidos por $100 \%$ de luminosidade, $70 \%$ de luminosidade e $50 \%$ de luminosidade, e quatro épocas de avaliações $(7,14,21$ e 28 dias após a emergência -DAE), verificaram que a diminuição da luminosidade provocou redução significativa da matéria seca de raiz e do volume médio de rabanete nas quatro épocas de avaliação, e no volume médio e produção de rabanete no momento da colheita final da cultura. A planta de rabanete demonstrou suportar índice de sombreamento de até 30\%, sem que haja reduções significativas de tamanho e massa de raízes tuberosas no momento da colheita.

O objetivo com este trabalho foi avaliar o efeito de diferentes níveis de tensões de água no solo na produção do rabanete cultivado em dois tipos de ambiente protegido. 


\section{MATERIAL E MÉTODOS}

O experimento com a cultura do rabanete (Raphanus sativus L.) foi instalado em duas estufas localizadas na área experimental do Departamento de Engenharia da Universidade Federal de Lavras, em Lavras, MG. As coordenadas geográficas da região são: latitude sul de $21^{\circ} 14^{\prime} 00^{\prime}$ e longitude oeste $45^{\circ} 00^{\prime} 00^{\prime \prime}$, com altitude média de, aproximadamente, $918 \mathrm{~m}$. O clima, de acordo com a classificação de Köppen, é caracterizado como Cwa, sendo temperado úmido com inverno seco e verão quente. A temperatura média do mês mais quente é de $22,8^{\circ} \mathrm{C}$, a do mês mais frio é de 17,1 ${ }^{\circ} \mathrm{C}$, e a média anual de $20,4^{\circ} \mathrm{C}$ (Dantas et al., 2007).

As estufas foram construídas com estrutura de madeira e cobertura metálica em arco, comprimento de $12 \mathrm{~m}$, largura de 7,0 m (área de $84,0 \mathrm{~m}^{2}$ cada casa), pé direito de $2,5 \mathrm{~m}$ e altura total de $4,0 \mathrm{~m}$ (pé direito + arco), rodapé com base de concreto e blocos de $0,20 \mathrm{~m}$ de altura. Em uma das estufas (convencional) foi utilizado filmes plásticos em polietileno transparente de 150 micra, com tratamento anti-UV na cobertura, e as fachadas laterais e frontais foram fechadas com tela antiafidica, em monofilamento de polietileno, cor branca, com aditivo estabilizador (anti-UV e antioxidante). Na outra estufa (modificada), também coberta com filmes plásticos em polietileno transparente de 150 micra com tratamento anti$\mathrm{UV}$, nas laterais e no seu interior, a $2,5 \mathrm{~m}$ de altura, foi instalada uma malha de transmissão de ondas na faixa do vermelho próximo e distante com, aproximadamente, $50 \%$ de sombreamento, denominada de ChromatiNet Vermelha ${ }^{\circledR} 50$.

$\mathrm{O}$ solo da área experimental foi classificado como Latossolo Vermelho Distroférrico (EMBRAPA, 1999). A curva característica de água do solo foi determinada no Laboratório de Relação Água-Solo-Planta do Departamento de Engenharia da UFLA. Foram coletadas amostras na camada de 0,0 a $0,30 \mathrm{~m}$ de profundidade. Com os dados de umidade do solo associadas às suas respectivas tensões, obteve-se o ajuste da curva de retenção de água no solo conforme modelo de Genutchen (1980), que descreve o comportamento da umidade do solo em função da tensão (Eq. 1).

$$
\theta=0,244+\frac{(0,325)}{\left[1+(0,2528 \cdot|\psi|)^{2,3606}\right]^{0,5764}}
$$

em que,

$\theta=$ teor de água atual $\left(\mathrm{cm}^{3} \mathrm{~cm}^{-3}\right)$; e

$\Psi=$ tensão de água no solo $(\mathrm{kPa})$.

No interior das estufas foi instalado um termohigrômetro digital, mod. HT-600, para monitoramento de temperaturas e umidades relativas máximas e mínimas, realizando-se as leituras diariamente às 12:00 $\mathrm{h}$ min. Neste horário foi realizado também leitura de energia solar (Medidor de Energia Solar, mod. MES100) e iluminação (Luximetro, mod. LDR-225), dentro e fora dos ambientes.A cultura utilizada no experimento foi o rabanete (hibrido Crunchy Royale).

Utilizou-se um delineamento experimental inteiramente casualizado (DIC), com quatro níveis de tensão de água no solo $(15,30,45$ e $60 \mathrm{kPa})$ e quatro repetições, em um total de 16 parcelas experimentais. Cada parcela experimental foi constituída de um canteiro com dimensões de 1,0 x 0,6 m. Em cada canteiro foi demarcado três linhas espaçadas de 0,20 $\mathrm{m}$ e o espaçamento entre plantas foi $0,08 \mathrm{~m}$. Os níveis de tensão de água no solo foi definido com base nos dados de Lima Júnior et al. (2012).

A adubação das parcelas experimentais foi realizada com base na análise de solo e de acordo com a recomendação da Comissão de Química e Fertilidade do Solo (Comissão, 2004). Foi utilizada na semeadura $40 \mathrm{~kg} \mathrm{ha}^{-1}$ de N, $90 \mathrm{~kg} \mathrm{ha}^{-1}$ de $\mathrm{P}_{2} \mathrm{O}_{5}$ e $130 \mathrm{~kg} \mathrm{ha}^{-1}$ de $\mathrm{K}_{2} \mathrm{O}$, correspondendo quantidade de adubo adicionado por canteiro de $12 \mathrm{~g}$ de sulfato de amônio, $30 \mathrm{~g}$ de super fosfato simples, $17,59 \mathrm{~g}$ de cloreto de potássio e adicionado $1 \mathrm{~kg}$ de substrato comercial por canteiro.

O sistema de irrigação utilizado foi localizada por gotejamento, com gotejadores espaçados de $0,20 \mathrm{~m}$, de vazão nominal de $2,3 \mathrm{~L} \mathrm{~h}^{-1}$ operando a uma pressão de serviço de $100 \mathrm{kPa}$. Foi instalada uma linha de gotejadores por canteiro, sendo a água proveniente de uma caixa com volume de $1000 \mathrm{~L}$, instalado próximo às estufas.

\section{REVENG}


O manejo da irrigação foi efetuado a partir da leitura média da tensão de água no solo, em tensiômetros instalados a $0,10 \mathrm{~m}$ de profundidade em todas unidades experimentais de 15, 30, 45 e $60 \mathrm{kPa}$. As leituras, com tensímetro digital, foi realizada diariamente às $12 \mathrm{~h}$. A irrigação era realizada quando a média das tensões apresentava valor próximo ao definido para cada tratamento. $\mathrm{O}$ tempo de irrigação foi definido pela Equação 2.

$$
T=\frac{((\theta c-\theta a) * z * A) / 1000}{(C U D) * E a * q}
$$

em que,

t é o tempo de irrigação em horas;

$\theta \mathrm{c}\left(\mathrm{cm}^{3} \mathrm{~cm}^{-3}\right)$ é o teor de água na capacidade de campo;

$\theta \mathrm{a}\left(\mathrm{cm}^{3} \mathrm{~cm}^{-3}\right)$ é o teor de água correspondente à tensão definida para irrigação de cada tratamento;

$\mathrm{z}(\mathrm{cm})$ é profundidade efetiva do sistema radicular; $\mathrm{A}\left(\mathrm{cm}^{2}\right)$ é área dos canteiros;

CUD é o coeficiente de uniformidade de distribuição igual a 0,93 (definidos pela relação entre a vazão média de $25 \%$ dos gotejadores com menores vazões e a média das vazões de todos os gotejadores); e

Ea é a eficiência de aplicação do sistema igual a 0,95 ; e q é a vazão dos gotejadores em $\mathrm{L} \mathrm{h}^{-1}$.

Da semeadura, realizada no dia 09/03/13 até 20/03/13, todos os tratamentos foram irrigados igualmente, ou seja, com a mesma quantidade de água, de forma a garantir a germinação e o pegamento das plântulas, procurando-se manter o solo com umidade próxima à capacidade de campo $(10 \mathrm{kPa})$.

Durante o ciclo da cultura foram adotadas medidas preventivas para controle de pragas e doenças e as capinas foram manuais e realizadas quando necessários.

A colheita foi realizada no dia 12/04. Em cada bloco foram colhidas 10 plantas e os bulbos foram separados da parte aérea, lavados e pesados em balança digital com a raiz e sem a raiz. O comprimento e o diâmetro do bulbo foram medidos com paquímetro digital. O comprimento da raiz foi medido com uma régua milimetrada. A área foliar foi medida utilizando um integrador de área foliar, modelo LI-3100, da marca Licor. Após as avaliações, a parte aérea da planta, a raiz e os bulbos foram embalados separadamente e levado para secar em estufa com circulação forçada de ar, à temperatura de $65^{\circ} \mathrm{C}$ até atingir peso constante, para determinação da matéria seca.

Os dados coletados foram avaliados estatisticamente através de análise de variância, a 1 e $5 \%$ de significância, com o auxílio do software SISVAR (FERREIRA, 2011).

\section{RESULTADOS E DISCUSSÃO}

Estão apresentados nas Figuras 1 e 2 os dados de temperatura do ar (atual, máxima e mínima) e de umidade relativa do ar (atual, máxima e mínima) registradas durante o experimento no ambiente convencional (representado pela letra B) e no ambiente modificado (representado pela letra V), respectivamente. Como pode ser observado a temperatura média do ar atual e a temperatura média máxima tende a ser maior no ambiente convencional, sendo a diferença média de 0,7 e $2,6{ }^{\circ} \mathrm{C}$, respectivamente. A temperatura média mínima tende a ser maior no ambiente modificado, sendo a diferença média entre os ambientes de 0,5 ${ }^{\circ} \mathrm{C}$. Kolcman e Sentelhas (2013) verificaram que a temperatura média do ar no ambiente com malha vermelha, com $70 \%$ de sombreamento, foi de 0,3 ${ }^{\circ} \mathrm{C}$ maior do que no ambiente coberto com filme de polietileno transparente sem uso de malhas de sombreamento.

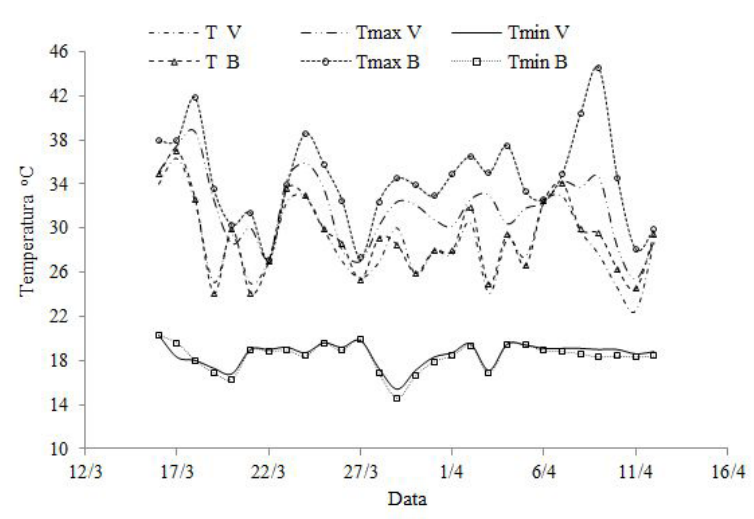

Figura 1. Dados de Temperatura atual (T), máxima (Tmáx) e mínima (Tmin) observadas nos ambientes convencional (B) e modificado (V). 


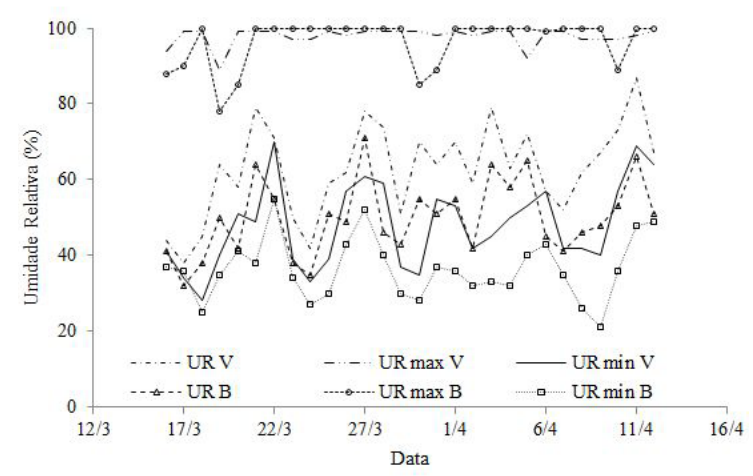

Figura 2. Dados de Umidade Relativa atual (UR), máxima (URmáx) e mínima (URmin) observadas nos ambientes convencional (B) e modificado (V).

A umidade relativa do ar máxima registrada nos dias 19, 20, 30 e 31 de março e no dia 10 de abril apresentou maior diferença entre os ambientes e tende a ser menor no ambiente convencional, porém não foi possível detectar a causa dessa diferença. Talvez tenha ocorrido algum problema com a leitura do higrômetro. A umidade relativa do ar atual e a mínima tende a ser maior no ambiente modificado. Os resultados observados por Holcman e Sentelhas (2013) para a umidade relativa do ar atual, no ambiente com malha vermelha, foi maior do que no ambiente coberto com filme de polietileno transparente sem uso de malhas de sombreamento. De acordo com os autores, a umidade relativa do ar tende a ser inversamente proporcional à temperatura e à intensidade de circulação do ar.

Estão apresentados nas Figuras 3 e 4 os dados de energia solar e iluminação fora e dentro dos ambientes, respectivamente. Nos dois ambientes, tanto a energia solar como a iluminação tende a ser menor do que na área externa e, no ambiente modificado, foram registrados os menores valores. No trabalho realizado por Holcman e Sentelhas (2013), verificou-se que no ambiente com malha de sombreamento vermelha a percentagem de radiação solar que efetivamente chegou até às plantas foi menor do que no ambiente coberto com polietileno transparente.

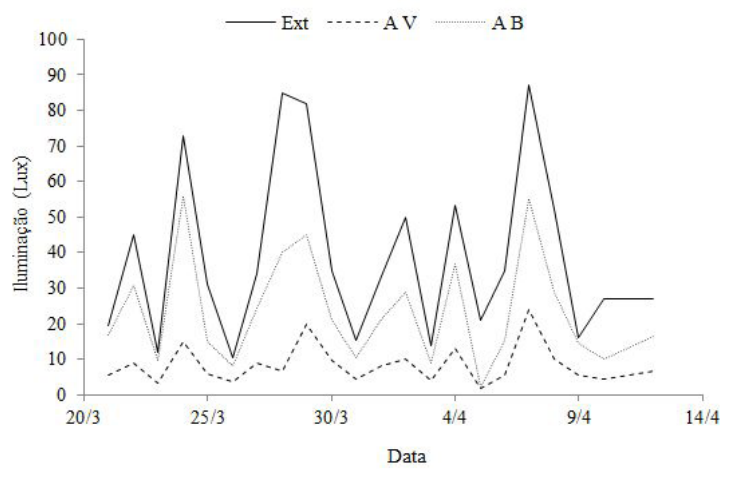

Figura 3. Dados de iluminação no ambiente externo (Ext) e dentro dos ambientes convencional $(\mathrm{AB})$ e no ambiente modificado (AV).

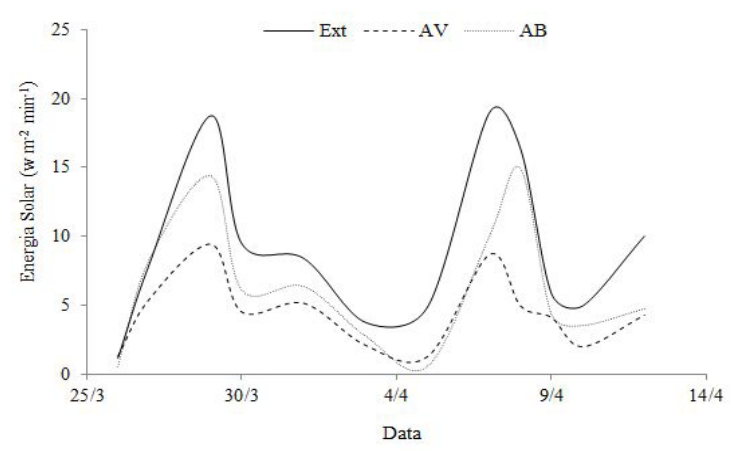

Figura 4. Dados de Energia solar no ambiente externo (Ext) e dentro dos ambientes convencional (AB) e no ambiente modificado (AV).

As lâminas de irrigação aplicadas nos dois ambientes a partir da semeadura até a colheita constam no Quadro 1. Durante doze dias, todos os tratamentos foram irrigados diariamente para garantir a germinação e pegamento das mudas. Posteriormente, a irrigação foi realizada conforme definido pelos tratamentos. Verifica-se que no ambiente com malha vermelha a lâmina aplicada e o número de irrigações foram menores do que no ambiente com polietileno transparente. No tratamento irrigado, quando a tensão da água no solo atingia $60 \mathrm{Kpa}$, nos dois ambientes, o número de irrigações e a lâmina aplicada foram iguais, tendo em vista que após a diferenciação dos tratamentos foi realizada somente uma irrigação. No ambiente com malha vermelha, a lâmina aplicada no tratamento de $60 \mathrm{kPa}$ foi realizada 4 dias após a aplicação no ambiente com polietileno transparente. $\mathrm{O}$ menor número de irrigação $\mathrm{e}$ 
lâmina registrada no ambiente com malha vermelha provavelmente se deve às condições do microclima prevalecente no ambiente.

Estão apresentados nos quadros 2 e 3 os resumos das analises de variância das médias de massa fresca do bulbo (MF bulbo) e da raiz (MF raiz), do comprimento da raiz (C raiz), do diâmetro longitudinal (DL) e transversal (DT) do bulbo de rabanete.

Nos dois ambientes as lâminas de irrigação aplicadas não influenciaram nas características avaliadas, porém, verifica-se que as médias da massa fresca do bulbo, do comprimento da raiz, do diâmetro longitudinal e transversal do bulbo tende a ser maior no ambiente convencional. A média da massa fresca da raiz tende a ser maior no ambiente modificado
Bregonci et al. (2008), trabalhando com rabanete cultivado em vaso, em casa de vegetação coberta com lona plástica transparente e subposta de sombrite com $30 \%$ de sombreamento, verificaram que o estresse hídrico aplicado em todas as fases fenológicas reduziu significativamente o diâmetro do bulbo e a massa fresca da raiz, quando comparado com a testemunha que foi irrigada durante todo o ciclo da cultura.

Um sistema de irrigação por gotejamento com seis frequências de irrigação foi avaliado por Wa e Kang (2006) na cultura do rabanete, no norte da China. Os pesquisadores verificaram que o desenvolvimento e a produtividade não foram influenciados pelos seis tratamentos, porém, a distribuição de raízes e a produtividade comercial foram significativamente influenciadas.

Quadro 1. Lâmina de irrigação aplicada (L) e o número de irrigações (NI) realizadas em cada ambiente durante o ciclo da cultura do rabanete.

\begin{tabular}{ccccc}
\hline Tensão em kPa & \multicolumn{2}{c}{ Amb. convencional } & \multicolumn{2}{c}{ Amb. modificado } \\
\hline & $\mathrm{L}(\mathrm{mm})$ & NI & $\mathrm{L}(\mathrm{mm})$ & NI \\
\hline 15 & 356,9 & 20 & 334,9 & 17 \\
30 & 340,5 & 15 & 326,1 & 14 \\
45 & 331,1 & 14 & 315,6 & 13 \\
60 & 317,1 & 13 & 316,6 & 13 \\
\hline
\end{tabular}

Quadro 2. Resumo da análise de variância para as médias de massa fresca do bulbo (MF bulbo) e da raiz (MF raiz) em gramas, comprimento da raiz (C raiz) em cm, diâmetro longitudinal (DL) e transversal (DT) do bulbo em cm em função dos tratamentos aplicados no ambiente convencional.

\begin{tabular}{ccccccc}
\hline Fonte de & Grau de & \multicolumn{4}{c}{ Quadrado médio } \\
\cline { 3 - 7 } variação & liberdade & MF bulbo & MF raiz & C raiz & DL bulbo & DT bulbo \\
\hline Tratamento & 3 & $14,8143^{\mathrm{NS}}$ & $0,0269^{\mathrm{NS}}$ & 3,5041 & $14,4265^{\mathrm{NS}}$ & $4,2218^{\mathrm{NS}}$ \\
erro & 12 & 161,4778 & 0,0226 & 3,1855 & 36,4440 & 21,7147 \\
Média & & 40,52 & 0,646 & 13,59 & 45,47 & 39,42 \\
CV (\%) & & 31,36 & 23,27 & 13,14 & 13,28 & 11,82 \\
\hline
\end{tabular}

NS Não significativo a $5 \%$ de probabilidade

Quadro 3. Análise de variância para as médias de massa fresca do bulbo (MF bulbo) e da raiz (MF raiz) em gramas, comprimento da raiz (C raiz) em cm, diâmetro longitudinal (DL) e transversal (DT) do bulbo em $\mathrm{cm}$ em função dos tratamentos aplicados no ambiente modificado.

\begin{tabular}{ccccccc}
\hline Fonte de & Grau de & \multicolumn{5}{c}{ Quadrado médio } \\
\cline { 3 - 7 } variação & liberdade & MF bulbo & MF raiz & C raiz & DL bulbo & DT bulbo \\
\hline Tratamento & 3 & $44,9334^{\mathrm{NS}}$ & $0,0245^{\mathrm{NS}}$ & $3,3556^{\mathrm{NS}}$ & $12,3036^{\mathrm{NS}}$ & $25,3737^{\mathrm{NS}}$ \\
erro & 12 & 65,1447 & 0,0198 & 2,4284 & 36,0506 & 27,4463 \\
Média & & 21,64 & 0,62 & 14,39 & 39,32 & 29,91 \\
CV $(\%)$ & & 37,25 & 22,72 & 10,83 & 15,27 & 17,52 \\
\hline
\end{tabular}

NS Não significativo a $5 \%$ de probabilidade 
No ambiente modificado a massa fresca média do bulbo foi de $21,64 \mathrm{~g}$, sendo $53,4 \%$ menor do que a massa fresca média observada no ambiente convencional. Verifica-se também que houve uma redução nos diâmetros longitudinal e transversal do bulbo. Como pode ser verificado na Figura 2, a energia solar e a iluminação tendem a serem menores no ambiente modificado e, como relatado por Souza et al. (1999), o sombreamento prolonga o ciclo, reduz o tamanho e o peso de raízes tuberosas e expande a área foliar. Schuster et al. (2012) relatam que a redução da radiação ou do fotoperíodo na cultura do rabanete inviabilizou a formação da parte comercializável. Segundo os autores, para a completa formação da raiz tuberosa é necessário que as folhas sejam expostas a fotoperíodos indutivos para iniciar a fase de tuberização, e que sejam mantidas nessa condição continuamente até a senescência de todas as folhas verdes.

Nos Quadros 4 e 5 estão apresentados os resumos das analises de variância das médias de massa seca do bulbo (Ms bulbo) e da raiz (Ms raiz), da folha (MS folha) e total (MS total) em gramas, e área foliar (AF) em $\mathrm{cm}^{2}$. Para estas características da cultura os tratamentos de irrigação não teve efeito significativo. Um dos fatores que pode ter influenciado nos resultados é o ciclo da cultura, de 35 dias, sendo que nos primeiros 12 dias todos os tratamentos, nos dois ambientes, foram irrigado com a mesma lâmina para garantir a germinação e pegamento das mudas.

Marques e Santos (2005) estudaram o efeito de diferentes níveis de irrigação com base na evaporação do tanque Classe A $(0,80,100 \mathrm{e}$ $120 \%$ ), sobre a produção do rabanete cultivado em vasos. Os autores verificaram que a matéria seca da parte aérea e das raízes não foram influenciadas pelos 3 níveis de irrigação, porém, houve diferença significativa entre o tratamentos irrigados e não irrigados.

Ao comparar a área foliar média entre os dois ambientes, verifica-se que no ambiente modificado a área foliar tende a ser maior do que ambiente convencional. A malha vermelha (ChromatiNet) muda o espectro da luz que a atravessa, reduzindo as ondas azuis, verdes e amarelas e acrescentando as ondas vermelha e vermelha-distante. Como

Quadro 4. Análise de variância para as médias de massa seca do bulbo (Ms bulbo), da raiz (Ms raiz), da folha (MS folha) e total (MS total) em gramas e área foliar (AF) em $\mathrm{cm}^{2}$, em função dos tratamentos aplicados no ambiente convencional.

\begin{tabular}{ccccccc}
\hline \multirow{2}{*}{$\begin{array}{c}\text { Fonte de } \\
\text { variação }\end{array}$} & Grau de & \multicolumn{5}{c}{ Quadrado médio } \\
\cline { 3 - 6 } & liberdade & MS bulbo & MS raiz & MS folha & MS total & AF \\
\hline Tratamento & 3 & $4,5951^{\text {NS }}$ & $0,0183^{\text {NS }}$ & $4,6443^{\text {NS }}$ & $17,6839^{\text {NS }}$ & $759603,45^{\text {NS }}$ \\
erro & 12 & 16,1272 & 0,0181 & 3,8384 & 28,7338 & 542072,98 \\
Média & & 14,74 & 0,512 & 10,57 & 29,96 & 3610,45 \\
CV $(\%)$ & & 27,25 & 26,29 & 18,52 & 20,65 & 20,39 \\
\hline
\end{tabular}

NS - não significativo a $5 \%$ de probabilidade

Quadro 5. Análise de variância para as médias de massa seca do bulbo (Ms bulb), da raiz (Ms raiz), da folha (MS folha) e total (MS total) em gramas e área foliar (AF) $\mathrm{em} \mathrm{cm}^{2}$, em função dos tratamentos aplicados no ambiente modificado.

\begin{tabular}{ccccccc}
\hline \multirow{2}{*}{$\begin{array}{c}\text { Fonte de } \\
\text { variação }\end{array}$} & \multirow{2}{*}{$\begin{array}{c}\text { Grau de } \\
\text { liberdade }\end{array}$} & MS bulb & MS raiz & MS folha & MS total & AF \\
\cline { 3 - 7 } & 3 & $4,9238^{\mathrm{NS}}$ & $0,1306^{\mathrm{NS}}$ & $10,8958^{\mathrm{NS}}$ & $28,9805^{\mathrm{NS}}$ & $2244301,02^{\mathrm{NS}}$ \\
Tratamento & 12 & 6,3459 & 0,0839 & 5,3637 & $21,91,83$ & 727396,29 \\
erro & & 8,88 & 0,56 & 10,36 & 19,85 & 4304,99 \\
Média & & 28,38 & 52,16 & 22,36 & 23,58 & 19,81 \\
CV $(\%)$ & & &
\end{tabular}

NS Não significativo a $5 \%$ de probabilidade 
conseqüência deste processo, as plantas cobertas com malhas vermelhas desenvolvem-se mais rapidamente; a superfície das folhas é maior; as hastes mais compridas e, em geral, o volume da folhagem é maior (POLISACK, 2013). Resultados semelhantes foram observados por Melo e Alvarenga (2009) em plantas de vinca, em que a área foliar foi significativamente influenciada pelo sombreamento, sendo os maiores valores verificados no ambiente com malha vermelha.

\section{CONCLUSÕES}

- Os resultados obtidos neste trabalho indicam que os níveis de tensões de água no solo não influenciaram na produção do rabanete;

- No cultivo em ambiente protegido com a malha de sombreamento vermelha $o$ desenvolvimento das raízes tuberosas tende a ser inferior ao observado no ambiente convencional, ao contrário da área foliar que teve um desenvolvimento mais acentuado.

\section{REFERÊNCIAS BIBLIOGRÁFICAS}

AGUILA, J.S.; SASAKI, F.F.; HEIFIGG, L.S.; ORTEGA, E.M.M.; JACOMINO, A.P.; KLUGE, R. A. Alteração do metabolismo respiratório em rabanetes minimamente processados. Revista Ciência Rural, Santa Maria, v.37, n.2, p.565-568, 2007.

AZEVEDO, L.P.; SAAD. J.C.C. Uso de dois espaçamentos entre gotejadores na mesma linha e seus efeitos na formação do bulbo molhado no solo e parâmetros físicos do rabanete. Irriga, Botucatu, v.17, n.2, p.148-167, 2012.

BREGONCI, I.S.; ALMEIDA, G.D.; BRUM. V.J.; JÚNIOR, A.Z.; REIS, E.F. Desenvolvimento do sistema radicular do rabanete em condição do estresse hídrico. Idesia -Chile, v.26, n.1, p.33-38, 2008.

CARMICHAEL， P.C.; SHONGWE， V.D.; MASARIRAMBI, M.T.; MANYATSI, A.M. Effect of mulch and irrigation on growth, yield and quality of radish (Raphanus sativus L.) in a semiarid sub-tropical environment. Asian Journal of Agricultural Sciences, v.4, n.3, p.183-187, 2012.

MANUAL DE ADUBAÇÃO E DE CALAGEM PARA OS ESTADOS DO RIO GRANDE DO SUL E SANTA CATARINA. Sociedade Brasileira de Ciência do Solo. Comissão de Química e Fertilidade do Solo. 10ed., Porto Alegre/RS, 2004, 400p. il.

COSTA, C.C.; OLIVEIRA, C.D.; SILVA, C.J.; TIMOSSI, P.C.; LEITE, I.C. Crescimento, produtividade e qualidade de raízes de rabanete cultivadas sob diferentes fontes e doses de adubos orgânicos. Horticultura Brasileira, Campinas. v.24, p.118-122, 2006.

DANTAS, A.A.A.; CARVALHO, L.G.; FERREIRA, E. Classificação e tendência climática em Lavras, MG. Ciência e Agrotecnologia, Lavras, v.31, n.6, p.1862-1866, 2007.

EMPRESA BRASILEIRA DE PESQUISA AGROPECUÁRIA. Centro Nacional de Pesquisa de Solos. Sistema Brasileiro de Classificação de Solos. Rio de Janeiro: Embrapa Solos. 1999. 412p.

FERREIRA, D.F. Sisvar: a computer statistical analysis system. Ciência e Agrotecnologia, Lavras, v.35, n.6, p.1039-1042, 2011.

GENUCHTEN, M.T.van. A closed-form equation for predicting the hydraulic conductivity of unsaturated soils. Soil Science Society of American Journal, Madison, v.44, n.1, p.898982, 1980.

HOLCMAN, E. SENTELHAS, P.C. Bromeliads production in greenhouse associated to different shading screens. Horticultura Brasileira, v.31, n.3, p.386-391, 2013.

KANG, Y.; WAN, S. Effect of soil water potential on radish (Raphanus sativus L.) growth and water use under drip irrigation. Scientia Horticulturae, Amsterdam, v.106, p.275-292, 2005. 
LIMAJÚNIOR, J.; PEREIRA, G.M.; GEISENHOJ, L.O.; SILVA. W.G.; VILAS BOAS, R.C.; SOUZA, R.J. Desempenho de cultivares de cenoura em função da água no solo, Revista de Engenharia Agrícola e Ambiental, Campina Grande, v.16, n.5, p.514-520, 2012.

MARQUES. P.A.A.; SANTOS, A.C.P. Efeito de diferentes níveis de irrigação baseado em frações do tanque Classe A sobre a produção do rabanete (Raphanus sativus L.). Colloquium Agrariae, v.1, n.2, p.23-27, 2005.

MELO, A.A.M.; ALVARENGA, A.A. Sombreamento de plantas de Chataranthus roseus (L.) G. Don 'Pacifica White' por malhas coloridas: desenvolvimento vegetativo. Ciência e Agrotecnologia, v.33, n.2, p.514-520, 2009.

NOMURA, E.S.; LIMA, J.D.; RODRIGUES, D.S.; GARCIA, V.A.; FUZITANI, E.J.; SILVA, S.H.M.G. Crescimento e produção de antúrio cultivado sob diferentes malhas de sombreamento. Ciência Rural, Santa Maria, v.39, n.5, p.13941400, 2009.

PEREIRA, E.R. Cultivo da rúcula e do rabanete sob túneis baixos cobertos com plástico com diferentes níveis de perfuração. 2002. 113p. Dissertação (Mestrado Agronomia, Área de concentração Irrigação e Drenagem)- Escola Superior de Agricultura "Luiz de Queiróz", Piracicaba, 2002.
PEREIRA, A.J.; BLANK, A.F.; SOUZA, J.R. OLIVEIRA, P.M.; LIMA, L.A. Efeito dos níveis de reposição e freqüência de irrigação sobre a produção e qualidade do rabanete. Revista de Engenharia Agrícola e Ambiental, Campina Grande, v.3, n.1, p.117-120, 1999.

POLISACK, Soluções em manejo do clima: ChromatiNet vermelha 50\%. Disponível em: http:// www.polysack.com/index.php?page_id $=254$, acesso em 22/11/2013.

SCHUSTER, M.Z.; KAWAKAMI, J.; BROETTO, D.; SZYMECZAK, L.S.; RAMALHO, K.R. O. Influência do fotoperíodo e da intensidade de radiação solar no crescimento e produção de tubérculos de rabanete. Pesquisa aplicada \& Agrotecnologia, v.5, n.2, p.73-86, 2012.

SOUZA, J.R.P.; MEHL, H.O.; RODRIGUES, J.D.; PEDRAS, J.F. Sombreamento e o desenvolvimento e produção de rabanete. Scientia Agrícola, Piracicaba, v.56, n.xx, p.987-992, 1999.

TORRES, C.A.S.; REBOUÇAS, T.N.H.; SIQUEIRA, L.G.; SILVA, J.C.G.; AMORIN, C.H.F.; CARDOSO, N.S. Avaliação da densidade de plantio sobre a produção e o diâmetro do rabanete. Horticultura Brasileira, Campinas, v.21, n.2. 2003, suplemento, CD-Room.

WA, S.; KANG, Y. Effect of drip irrigation frequency on radish (Raphanus sativus L.) growth and water use. Irrigation Science, New York, v.24, p.161-174, 2006. 